\title{
Sources of Nigerian Architecture in the 21st Century
}

\author{
Moukhtar M. Mai ${ }^{1}$ and Sani I. Khalil ${ }^{2}$ \\ 1. Department of Architectural Technology, School of Environmental Studies, Federal Polytechnic Nasarawa, Nasarawa \\ State,252976, Nigeria
}

2. Department of Architecture, Faculty of Arts \& Environmental Sciences, Bayero University, Kano 729725, Nigeria

\begin{abstract}
Nigeria, the home of the largest conglomeration of blacks in the world, deserves its unique architectural identity. Its variety of vernacular built environment seems to hold promise to that ambition. Vernacular architecture across Nigeria's geographical clusters has demonstrated a thorough response to the climate, local technology and socio-economic parameters in which they developed. The advent of colonialism, the spread of Islam in Africa, and the end of slave trade, impacted tremendously on the options available to developers and master builders over the years. This review paper identifies the prospective sources of evolving the country's unique spatial identity and architectural language by critically exploring the determinant and moderating factors of the development of ethno-regional built environment for the country. The life style and the divergent historical circumstances of the nation's core subdivisions readily suggest the devolution regional identities. The paper argues that a national identity could be forged through a five-tier synthesis of architectural strategies, to positively integrate form, space, and order imaginatively to fit user "genius loci”, i.e. sense of rootedness. The application of the courtyard within the family compound (groups of dwelling units sharing common services), serves physical, social, and economic functions concurrently. Hence, the essence of traditional style has to be cherished dearly, to ensure cultural heritage conservation of the society. It could be concluded that despite the gradual replacement of traditional building practices with modern trends; core cultural values like hierarchic selective interaction (privacy) afforded by the courtyard housing system, seem to be retained as consistent features of Nigeria's build environment, which must be jealously guarded.
\end{abstract}

Key words: National identity, vernacular architecture, form, space, culture.

\section{Introduction}

The challenges of establishing methods and materials that hold promise towards the development of a country's architecture are the task of this study. It argues that the nation's history, geography, sociology, natural images and technological development, could be carefully conceptualized individually and collectively as inspirations for a national identity for its built environment. Therefore, it reviews the eclectic ideas to fulfill this mission. Architectural identity refers to the discontinuous contemporary context across time as its formation is influenced by prevailing ideas, practices, or broad conditions, all of which are specific to an era in history. The aim of this

Corresponding author: Mukhtar M.Mai, Dr., research fields: housing and culture.

Ibrahim Sani Khalil, Dr., research fields: sustainability, culture and regulation. paper is to contribute to the current discussion on evolving a Nigerian architecture. It proposes five (5) strategic steps of creating a genius locus, which could be perceived as a psychological sense of identity of place. This paper is in six (6) sections. Following this introduction, which spells out problem statement, as well as the theoretical orientation, is the outline of the five hierarchic layers of sourcing Nigerian architectural identity based on genius loci. Subsequently, the five (5) strata were logically treated in sections. Section 6 concludes the paper with a schematic model.

\subsection{Genius Loci as Architectural Identity}

Martin Heidegger (1957) in Czumalo [1] conceptualizes mankind's spatial identity by considering the verb "to live" in its wider spirit. It suggests that respective cultural groups' way of 
undertaking their journey from their birth to death (life cycle) under vault of heavens. Norwegian historian and architectural theorist Christian Norberg-Schulz [2] aptly supplements Heidegger's definition of habitation and demonstrates the extent to which individual identity leads to spatial identity, sense of belonging to a place. He also shows how human beings create objects of identification in the process of building and discovering their peculiar identity.

\section{The Five Hierarchic Layers Sourcing Nigerian Architecture}

The developer's sense of rootedness to the environment is enough motive to evolve a unique scheme, to meet peculiar user needs. This involves first architectural classification; second, the assessment of the traditional built environment (of the proposed scheme) in terms of response to context such as, the architecture of the veil; third, the application tacit knowledge of the design process culture. The fourth step involves poking into nature for conceptual design inspiration. Finally, it is the synthesis of the four previous layers in order to establish the core characters of the country's identity that are tied to genius loci.

\subsection{Architectural Classification}

The prospects of national identity are quite promising especially from the variety of the nation's architectural styles emanating from ecological, historical, and socio-cultural circumstances of the six geo-political zones of the country. For a start, categorization of the country's architecture lends a platform for the devolution of a national identity.
Despite the lack of consensus on the actual classes of styles, such groupings may be a simple basis for the evolution of a unique identity for the country. For instance, Pruscal-Ogunsote [3] classified of Nigerian architecture into historical, traditional and modern styles. The historical style is represented by the European, Brazilian and North African trends. The traditional architecture manifests in "cone upon cylinder" (thatch roof placed on mud wall). And the modern style includes the international style, the new West African style and the post-modern movement. She noted a very weak link between the historical style cum traditional architecture and their contemporary counterparts in Nigeria. The historical style reveals that architects' inspirations were drawn from ancient heritage as evidenced by the regional contemporary trends. Fig. 1 below is a hypothetical representation of this evolutionary tilt based on technological progress. The three classes depict careful response to the careful design forces such as affordability, site context, and user world view.

Jonathan [4] grouped the country's architecture into five (5) as follows: (i) Nigerian ancient architecture (NAA); (ii) Nigerian traditional architecture (NTA); (iii) Nigerian colonial architecture (NCA); (iv) Nigerian modern architecture (NMA); and (v) Nigerian architecture today (NAT). This classification is very similar to Pruscal-Ogunsote's [3] as both of them concur on traditional architectural style. However, Jonathan [4] splits Pruscal-Ogunsote's historical style into ancient and colonial versions. Similarly, he separated contemporary from modern Nigerian architecture.
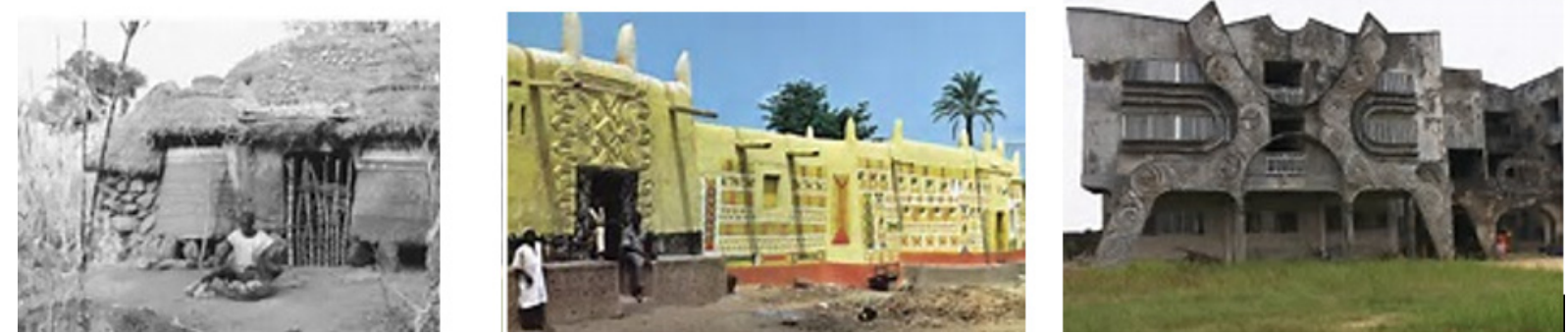

Fig. 1 Sample representation of Pruscal-Ogunsote's (2001) three-tier evolutionary trend of Nigerian architecture. 
Jonathan [4] opined that the major influence of the NTA on evolution of Nigerian architecture manifests in both modern and colonial built environments. Here, the NAA covers the global ancient/antiquity era, while the NTA covers the Middle Ages (the feudalism and renaissance period). Moreover, the NCA and NMA, covers the industrial revolution of 19th and 20th centuries' technological/scientific revolution era, but, the NAT covers the knowledge society of 21 st century [4]. Alabi in NIA Journal [5] grouped indigenous Nigerian architecture into those monumental buildings, secretariat, and government reserved areas (GRA), where most of whose had functional aesthetics that promote natural cross ventilation. Each of the above classification could be tested in the creation of a national identity.

\subsection{Assessment of the Traditional Built Environment}

The development of Nigeria's built environment was influenced by the forces of colonialism, the spread of Christianity from the Atlantic Ocean to the hinterland, the trans-Saharan trade, spread of Islam from the Sahara Desert southwards, and the return of freed of slaves from Brazil through Free Town, Serra Leone. The coastal Southern Nigeria was influenced mostly by Brazilian and colonial architecture. But, the North adopted Islamic traits brought by the Arab traders from North Africa which later developed into Hausa traditional architecture [6]. These pervaded monumental buildings in Northern Nigerian cities such as emir's palaces in Bauchi, Zaria, Kano and Yola.

Nationwide, the traditional built environment manifests in the application of local building materials and construction technology, both of which have rich lessons that could be abstracted for application in vernacular or contemporary sensibility. Psychologically, the architecture of the veil emphasizes introverted aesthetics and compliance to Islamic dictates of shielding women from the preying eyes of male visitors, as well as passers-by. This was corroborated by Agboola and Zango's [7] assessment of traditional buildings across Nigeria's six (6) geo-political zones demonstrated a thorough response to the specific environmental settings, local technology and socio-cultural and economic locale in which they evolved. They opined that the origin and subsequent growth of the variety culture specific edifices was closely associated with the natural materials accessible to the local artisans, their respective spiritual inclinations to cultural ethos and taboos. The construction technology and the architectural styles in Figs. 2 to 4 below could be evaluated for the extraction revolutionary design guidelines to meet national interest.

\subsubsection{Veil as a Metaphor}

Veil literally means cloth, mask, curtain that screens an object. Within the built environment, it is a permanent or temporary device that shades either an outdoor or indoor setting. The concept functions both as a literal, and as a complex metaphor of gender segregation. Wearing the veil in the Muslim context, shields the woman's body from a male's (potential predator) gazes. Islamically, it psychologically guards the chastity of women, and discourages promiscuity by suggesting
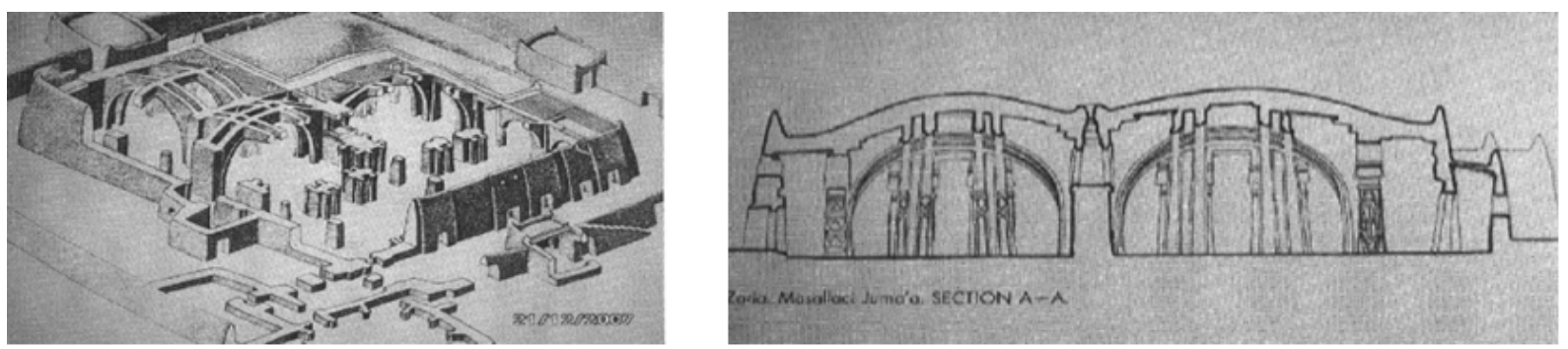

Fig. 2 Left to right-an isomeric view of the old Zaria Central Mosque; a section through the Mosque.

Source: adapted from Adeyemi [8]. 

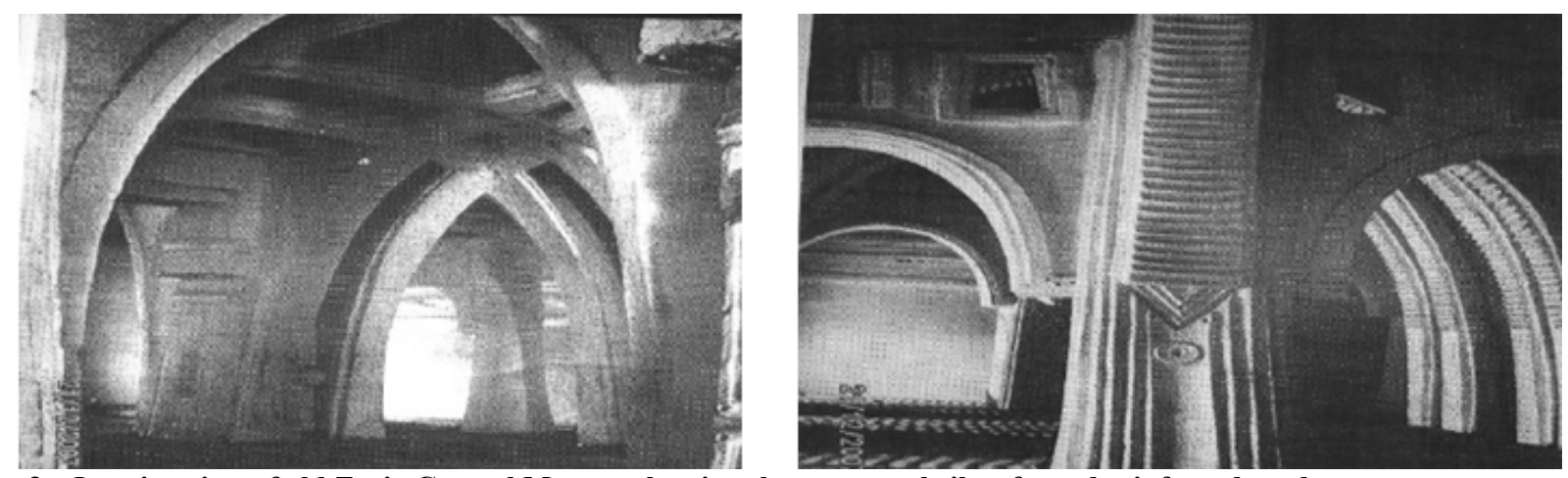

Fig. 3 Interior view of old Zaria Central Mosque showing the structural ribs of wood reinforced mud. Source: adapted from Adeyemi [8].
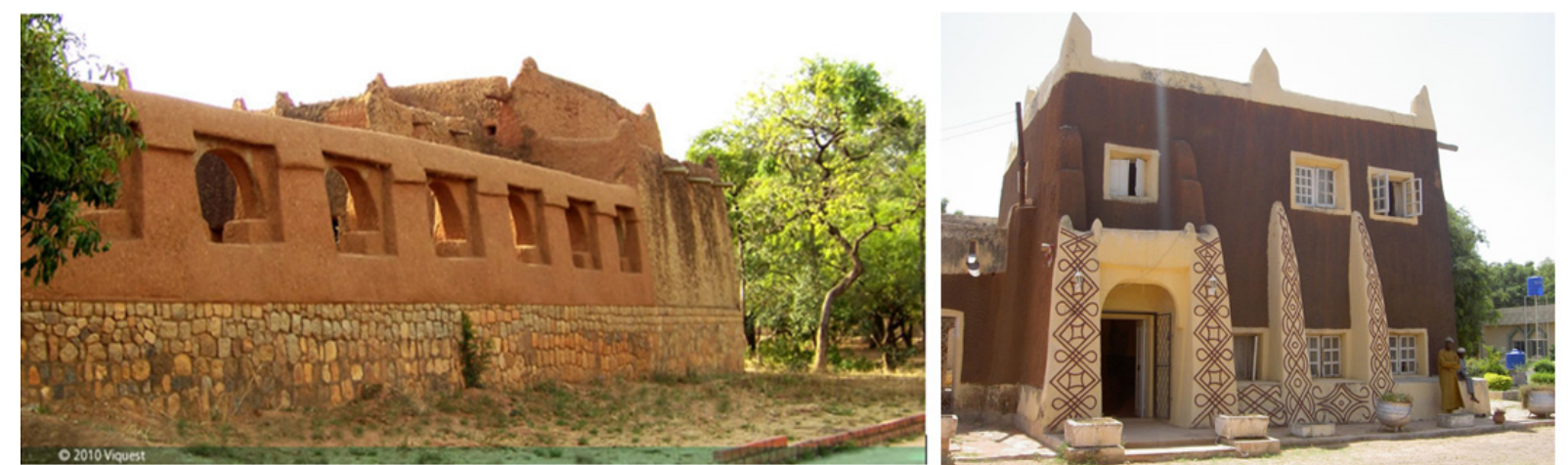

Fig. 4 Left to Right-A typical royal fence of Katsina Emir's Palace at MOTNA, Jos; A typical Hausa traditional architecture of Northern Nigeria.

a "keep off" syndrome, hence, its adoption as a core principle of Islamic built environment. Emotionally, this design code appropriately ensures strict hierarchy spaces in Islamic settlements of Northern Nigeria. The most striking feature of Islamic architecture is the focus on interior space as opposed to the outside or facade. The most typical expression of this focus on inner space is in the most Muslim compounds (group of residences sharing common services). Typically, houses are characterized rooms organized around an inner courtyard. The facade of this house offers high windowless walls interrupted only by a single low door. In some cases, high level windows are provided on the external world.

\subsection{Application Tacit Knowledge of Cultural Design Process}

The justification for the design process culture seems to be the combination of historical and cultural circumstances of the studio practice. In general, the understood tacit nature of design knowledge (silent, unspoken, implied and inferred); and architectural design in particular, believes in learning by doing, which involves trial and error. Tacit knowledge is characterized by difficulty to either document or transfer. Therefore, the studio culture affords the transfer of tacit knowledge through the master-apprentice format of on the "on-the-board" educational system. Here, apprentices are coached through personal experience, narrative, and hands-on practice [9]. The success of an architectural proposal within its context of its application depends upon [9]:

(1) The comprehension of the structure of the process;

(2) The alignment of the selected elements with the core priorities of the scheme; and

(3) The designer's ability to set appropriate priorities, to create intentions, and make decisions accordingly. 
It is the role of the designer, and not to suggest the design methodology, but to create intentions relevant to the identification priorities, hence makes appropriate decisions accordingly. Design intentions need to be connected to outcomes which are testable; otherwise we are falling into the fallacy of being romantically speculative about the power of vague ideas.

The Osasona [10] examined the impact of British colonial architectural practices and the Afro-Brazilian style (which they facilitated), on the traditional architecture of Southern Nigeria. It sets forth the transition to vernacular practices and the transformations engendered - particularly in the light of rural, semi-urban and highly-urbanized variants. It is submitted that what comes closest to a vernacular prototype, does a floor-plan comprise four rooms or more, directly opening out on to an exaggerated centrally-positioned corridor, with conveniences and utilities to the back of the house. Architectural embellishment, initially highly ornate in the original Afro-Brazilian stylistic prototype, has become extremely minimal. "Meaning", both in its functional and symbolic contexts, is presented as being inherent in both the traditional and vernacular expressions of Nigerian architecture, north and south of the country. Of necessity, such connotations are transforming in response to changing cultural needs.

\subsection{Nature as Conceptual Design Inspiration}

The balanced natural system could be mimicked in terms of its harmony, rhythm and variety. Such inspirations could be applied as concepts for the evolution of a national identity. Vahedi [11] argued that architecture design works that imitate nature closely were yet not perfect due to some missing parts in one of their forms, function, or structure. This being the nucleus of the design process; is the point at which the form, space, order or character, and design details of each project could be best identified and confirmed. Architecture is perhaps the most enduring and expressive of all the types of material culture. As a medium, architecture has a language, or rhetoric of its own; the elements used invoke various historical allusions and ideological connotations. As anthropologist Victor Buchli [12] asserts that often, the way to comprehend a given society is to understand the physical and, by metamorphic extension, the social architecture of its organization. Architectural organization inherently reflects in itself in the styles and elements it employs, an affinity or an agenda for proper execution.

\subsection{Creative Inspiration}

Nigeria's biodiversity and multi-cultural nature could inspire architects to develop innovate schemes that portray the nation's uniqueness. Creativity is the capacity to innovate, create and convert original ideas into tangible objects. Generally, the generation of creative ideas manifests in a sudden illumination, which occurs after a large amount of mental tasking. The creative designer regularly solves problems (Fig. 5), styles products or defines new enquiries relevant to the project being executed or designed, in a way that is initially considered novel but that ultimately becomes accepted in a particular cultural setting [13]. Design is often explained as defining a problem then optimizing a derived solution to the problem. The designer's role is to embody the problem and solutions and then create something of worth after deep thought and investigation. In other words, creative process involves five (5) hierarchic levels of recognition, preparation, incubation, illumination, and verification. 

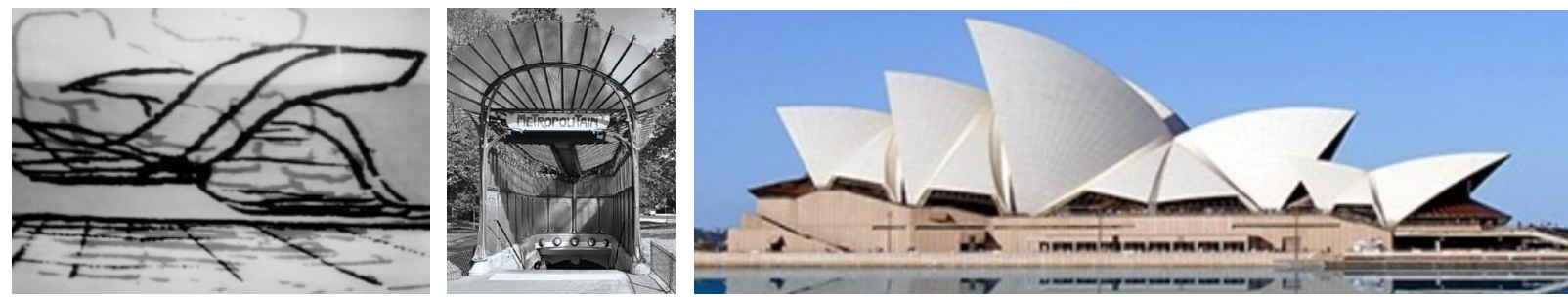

Fig. 5 "Clouds over a plaza" was the idea behind the design of the Sydney Opera House by Danish architect Jørn Utzon. M: Porte Dauphine Paris Metro entrance, France by Hector Guimard. Plant forms inspired his innovative forms and the creative detail, which is reminiscent of art noveou (new art in French). R: The Sydney Opera House by Danish architect Jørn Utzon. Its design was inspired by "clouds over a plaza" whose initial sketch is shown above left.

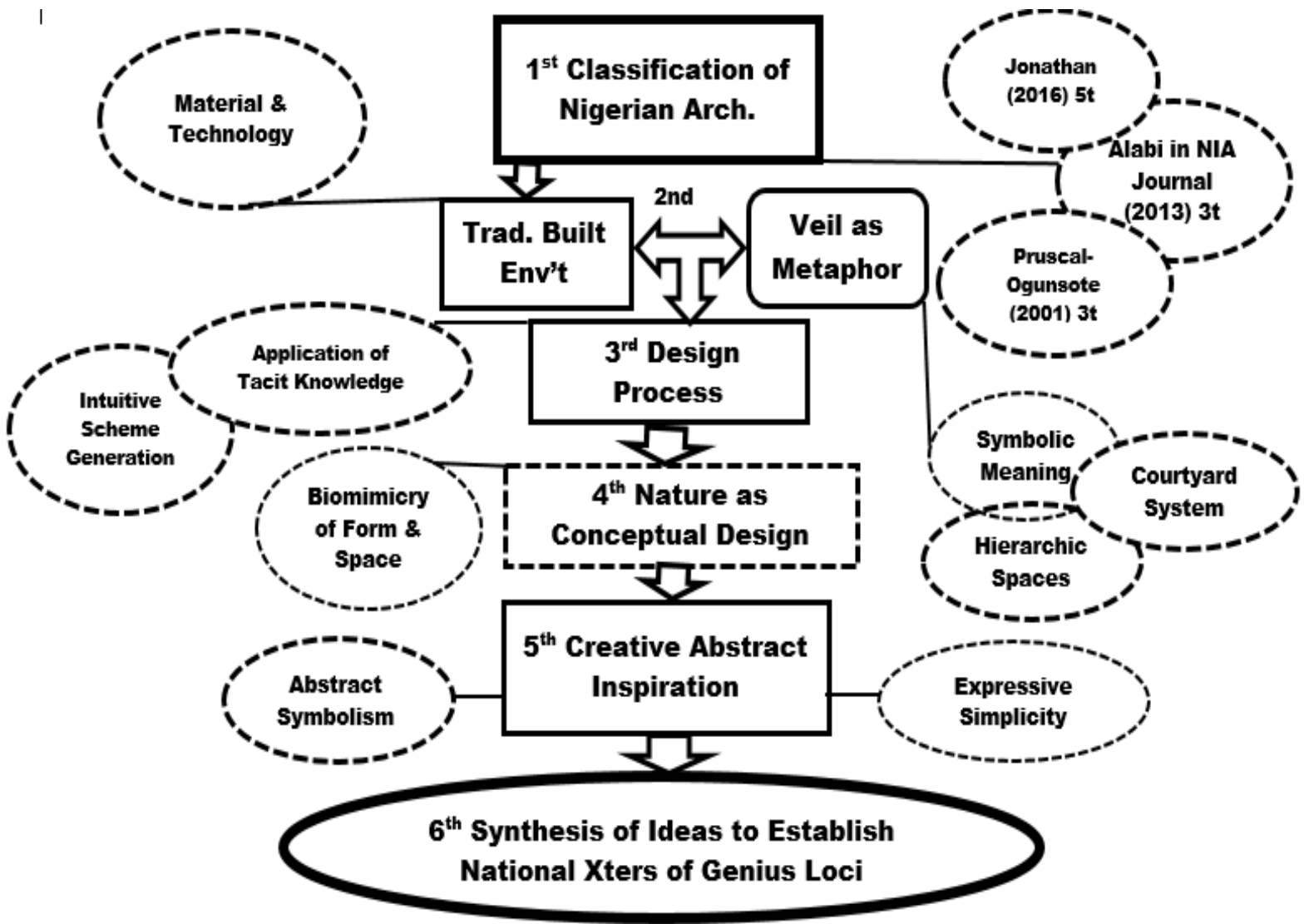

Fig. 6 A schematic model of developing Nigerian architecture.

\section{Conclusion}

As suggested the schematic model above in Fig. 6, the Nigerian architectural identity could be sourced from variety ideas, such as building classes, natural concepts, design process culture, natural inspirations, and spatial identity. Whichever way, priority should be given to functional aesthetics fitted for energy conservation. The latent ideas emanating from the design process culture seem to be a jack pot of fresh thoughts for the task of developing a distinctive character. Design metaphor is another promising strategy of achieving a national identity. However, cyclic yo-yo approach to all the five steps could also be tested in establishing the desired design process required for the mission.

\section{References}

[1] Czumalo, V. 2012. "Architecture and Identity." Autoportret 1 (36): 46-52.

[2] Norberg-Schulz, C. 1979. Genius Loci: Towards a Phenomenology of Architecture. New York: Rozzoli.

[3] Pruscal-Ogunsote, B. 2001. "Classification of Nigerian 
Architecture." ARCHES Journal 6: 48-56.

[4] Jonathan. 2016. "Nigerian Architecture." Accessed July 9, 2017. http://www.thearchitecthistorian.com/2016/11/16.

[5] NIA Journal. 2013. Journal of the Nigerian Institute of Architects, June-September. ISBN No. 23158913.

[6] Rikko, L. S., and Gwatau, D. 2011. "The Nigerian Architecture: The Trend in Housing Development." Journal of Geography and Regional Planning 4 (5): 273-8. http://www.academicjournals.org/JGRP.

[7] Agboola, O. P., and Zango, M. S. 2014. "Development of Traditional Architecture in Nigeria: A Case Study of Hausa House Form." International Journal of African Society Cultures and Traditions 1 (1): 61-74.

[8] Adeyemi, E. A. 2008. "Meaning and Relevance in Nigerian Traditional Architecture: The Dialectics of
Growth and Change." Public Lecture Series 1 (21): 1-33.

[9] Bachman, L. R. 2012. Two Spheres: Physical and Strategic Design in Architecture. Abingdon \& New York: Routledge, 6.

[10] Osasona, C. O. 2007. "From Traditional Residential Architecture to the Vernacular: The Nigerian Experience." http:www.mainline.Org/aat/2007_docum ents/AAT. Osasona, 17-19.

[11] Vahedi, A. 2009. "Nature as a Source of Inspiration of Architectural Conceptual Design.” Master thesis, Eastern Mediterranean University, Gazimağusa, North Cyprus.

[12] Buchli, V. 2013. An Anthropology of Architecture. London: Bloomsbury Publishing.

[13] Schön, D. A. 1983. The Reflective Practitioner: How Professionals Think in Action. New York: Basic Books. 